\title{
Transtorno de Jogo: contribuição da abordagem psicodinâmica no tratamento
}

\author{
Maria Paula Magalhaes Tavares de Oliveira* (i) \\ Juliana Saldanha de Castro \\ Edilson de Oliveira Braga (1) \\ Bruno Chagas Raszeja $(\mathbb{D}$ \\ Universidade de São Paulo, Faculdade de Medicina, Instituto de Psiquiatria, São Paulo, SP, Brasil
}

Resumo: Jogos de azar podem ser uma atividade de lazer, mas sua prática em excesso pode levar a consequências adversas, como o Transtorno de Jogo. Apesar dos sérios prejuízos provocados por esse quadro, tanto o Transtorno de Jogo em si quanto estratégias de tratamento são pouco conhecidos no Brasil. Este trabalho aborda o Transtorno de Jogo e seu tratamento, tendo como objetivo explicitar a contribuição da abordagem psicodinâmica. São apresentadas as principais hipóteses psicodinâmicas existentes na literatura e tecidas considerações sobre a psicoterapia psicodinâmica realizada em um serviço que atende jogadores em São Paulo, o Programa Ambulatorial do Jogo Patológico (PRO-AMJO) do Instituto de Psiquiatria do Hospital das Clínicas da Faculdade de Medicina da Universidade de São Paulo (IPq HC-FMUSP). Por fim, alguns exemplos de perfis de jogadores patológicos são apresentados.

Palavras-chave: Transtorno de Jogo, jogo patológico, tratamento, psicodinâmica, psicoterapia.

\section{Introdução}

O jogo tem papel relevante no desenvolvimento humano. Huizinga (1938/1999), em seu célebre livro Homo Ludens, afirma que o jogo é mais antigo do que a cultura. As brincadeiras da infância preparam o indivíduo para a vida adulta. Crianças brincam e os jogos vão ficando mais complexos conforme crescem. Jogos de imaginação, de contato físico, tabuleiro e inúmeros outros apresentam diversos desafios e regras que auxiliam no preparo para o enfrentamento de dificuldades inerentes à vida. A competição, o desejo de ganhar, de ser bem-sucedido, são elementos inerentes à ação de jogar. Em jogos de habilidade, é possível treinar para alcançar o objetivo almejado, mas há outros jogos em que o acaso tem papel central, como nos jogos de azar.

Presente em diversas culturas e em diferentes épocas da história, jogos de azar atraem o ser humano. Dostoievsky (1866/1987), no romance O jogador, retratou bem esse fascínio, descrevendo inclusive sensações físicas experimentadas pelos jogadores patológicos. A recompensa pode vir a qualquer momento, o que provoca excitação e reforça o comportamento do indivíduo, estimulando-o a continuar a apostar na esperança de ganhar ou de recuperar perdas de apostas anteriores. Quanto mais rápido vier a recompensa, maior o poder aditivo do jogo. Não é sem motivo o tempo mínimo de intervalo entre rodadas em bingos e a atração provocada pelos jogos eletrônicos ou virtuais, que além de serem rápidos, fascinam com suas luzes e sons. A tecnologia aumenta o poder aditivo dos jogos, tornando-os mais sofisticados, interessantes e

\footnotetext{
* Endereço para correspondência:mpm_fto@uol.com.br
}

atraentes. Geralmente, um ambiente é forjado para causar distração, e o indivíduo que nele está consome tempo e parte considerável de seus recursos sem perceber.

No Brasil, jogos de azar estão proibidos desde 1946. Todavia alguns tipos de jogos envolvendo apostas, tais como loterias e corrida de cavalos, permaneceram permitidos, enquanto outros operam na ilegalidade (Tavares, 2014). Sob o pretexto de ser esporte de habilidade, campeonatos de pôquer vêm crescendo e se popularizando. Atualmente, há forte pressão para legalização de jogos de azar no país, sob o argumento de gerar empregos e trazer renda para o Estado.

Custer (1984) descreve três fases características do comportamento de jogar: (1) fase da vitória: a sorte inicial é rapidamente substituída pela habilidade no jogo e o indivíduo passa a jogar mais, com maior frequência; (2) fase da perda: prepondera uma atitude de otimismo não realista que passa a ser característica de jogador patológico, o valor da aposta aumenta consideravelmente, utilizando-se economias e contração de dívidas, a perda é difícil de ser tolerada e o indivíduo passa a jogar sozinho; (3) fase do desespero: há consumo maior de tempo e dinheiro, e afastamento da família. Na literatura, há diversas classificações de jogadores, de acordo com o grau de envolvimento com a atividade: jogador social, jogador profissional, jogador de risco, jogador-problema, jogador compulsivo, jogador patológico, sendo os últimos termos utilizados para nomear indivíduos que apresentam desejo incontrolável de jogar e sofrem consequências adversas.

Em 1980, o Jogo Patológico foi reconhecido como patologia e incluído no DSM-III (American Psychiatric Association, 1980) como Transtorno do Controle do Impulso Não Classificados em Outro Lugar, caracterizado 
por comportamento mal adaptativo, persistente e recorrente de apostar, com prejuízos nos âmbitos pessoal, familiar e profissional. Em 2013, na edição do DSM-V (American Psychiatric Association, 2013), o Transtorno de Jogo (TJ) passou a figurar dentre os Transtornos Relacionados a Substâncias e Adição. Problemas relacionados a jogos de azar afetam de 0,2\% a 4\% da população (Petry, Ginley, $\&$ Rash, 2017). Transtornos de humor, de ansiedade e dependência de substâncias são comorbidades psiquiátricas frequentemente presentes (Petry, Stinson, \& Grant, 2005) e associadas à maior gravidade de TJ (Desai \& Potenza, 2008; Petry et al., 2005). Também foi observado aumento de psicopatologia quando há comorbidade com dependências comportamentais, principalmente compulsão alimentar (Tang, Kim, Hodgins, McGrath, \& Tavares, 2020). Estudo epidemiológico conduzido no Brasil revelou que $12 \%$ dos brasileiros apostam pelo menos uma vez por mês. Cerca de $1 \%$ preencheu critérios para TJ e 1,3\% para jogo-problema ao longo da vida (Tavares et al., 2010). Comparado com outros estudos de prevalência de dependências no Brasil, o TJ seria a terceira dependência mais prevalente no país, atrás apenas do tabaco e do álcool.

Entretanto esse diagnóstico ainda é desconhecido por parte da população, que adjetiva o jogador de "mau caráter" e ignora a existência de tratamento apropriado (Oliveira, 2009). Mladenoviü, Lažetiü, Lepiü-Toševski e Dimitrijeviü (2015) apontam que muitos profissionais não se sentem preparados para identificar tampouco tratar TJ. Em estudo recente na Suécia, Håkansson \& Ford (2019) concluíram que, na população geral, muitos acreditam que o TJ não requer tratamento profissional e recomendam suporte fora do sistema formal saúde.

No Brasil, é escassa a oferta de tratamento para esse transtorno. Poucas cidades contam com Grupos de Jogadores Anônimos (JA). Em São Paulo, o Programa Ambulatorial de Jogo Patológico (PRO-Amjo), do Instituto de Psiquiatria do Hospital das Clínicas da Faculdade de Medicina da Universidade de São Paulo, oferece um programa de tratamento a jogadores desde 1997. Este serviço não se restringe a tratar apenas os sintomas relacionados ao jogo, mas propõe uma abordagem mais ampla, visando a mudanças de atitude perante a vida (Tavares, 2014). O PRO-Amjo conta com uma equipe multidisciplinar responsável por várias modalidades terapêuticas: avaliação e acompanhamento psiquiátrico, entrevistas motivacionais, psicoterapia individual, grupal e familiar. O programa oferece também grupos pósterapêuticos, como educação física, qualidade de vida e meditação, entre outros. O presente trabalho se propõe a discutir a especificidade da psicoterapia de orientação psicodinâmica (PP) com esses pacientes.

\section{Tratamento para portadores de Transtorno de Jogo}

Diversas abordagens têm sido empregadas no tratamento de TJ (Oliveira \& Silva, 1998). Segundo
Walker et al. (2006), o tratamento pode abranger três pontos distintos: supressão do comportamento de jogo problemático, redução das consequências negativas relacionadas ao jogo e, por último, a promoção de saúde e de qualidade de vida. Diferentes estratégias podem ser escolhidas para atingir esses objetivos: terapia farmacológica, psicoterapia grupal ou individual, familiar, grupos educacionais ou motivacionais, grupos de aconselhamento e atividade física. Kraus, Etuk e Potenza (2020) apontam que há poucos estudos controlados de farmacoterapia para TJ e que a combinação com psicoterapia apresenta melhores resultados.

Fong (2005) descreve as principais formas de psicoterapia que vêm sendo utilizadas no tratamento de TJ: Jogadores Anônimos (JA), terapia cognitivo comportamental (TCC), terapia comportamental (TC), psicoterapias psicodinâmicas (PP), psicoterapia familiar, redução de danos e linhas de apoio. Em síntese, no grupo de JA, as reuniões são gratuitas e seguem o modelo de autoajuda de 12 passos, semelhantes ao utilizado para abuso de álcool (AA) e de outras substâncias (NA). Na TCC, pautada por reestruturação cognitiva, há um número de sessões delimitado e seus principais objetivos são identificar pensamentos negativos, distorções cognitivas, bem como percepções errôneas sobre jogos de azar, consideradas responsáveis por manter esse comportamentoo. Já na TC, procura-se remodelar o comportamento mudando as respostas aprendidas e reduzindo a excitação ou outras sensações gratificantes experimentadas no jogo. Segundo Fong (2005), na PP procura-se identificar o significado por trás do jogo excessivo e os conflitos que podem ter levado a esse quadro clínico. Na psicoterapia familiar, por sua vez, o foco se concentra na identificação de dinâmicas familiares problemáticas, visando à diminuição de conflitos intrafamiliares. As intervenções na perspectiva da redução de danos são voltadas para controlar ou limitar o jogo, e não para manter a abstinência. Existem também linhas de apoio que oferecem profissionais de saúde treinados para fornecer suporte e informações sobre TJ.

Mladenoviü et al. (2015) apontam para a complexidade do tratamento de jogadores e propõem um modelo multissistêmico que procura integrar terapia familiar e TCC, com traços de abordagem psicodinâmica, existencial e farmacoterapia. Em revisão sistemática sobre tratamento para TJ, Petry et al. (2017) selecionaram 21 estudos randomizados com diferentes abordagens (TC, TCC, entrevista motivacional e feedback) e concluíram que nenhuma mudança consistente ou persistente foi observada em qualquer tratamento específico.

Em estudo de metanálise, Shedler (2010) demonstra evidência empírica de que os efeitos da PP são semelhantes aos de outros tratamentos baseados em evidências. A PP promove processos que levam a mudanças mesmo depois do término da terapia. O autor conclui que, além da remissão de sintomas, a PP estimula recursos internos que levam a uma vida interior mais satisfatória. Não há estudos controlados sobre eficácia de PP especificamente para TJ 
(Stea \& Hodgins, 2011). Estudos indicam a eficácia da abordagem psicodinâmica para tratamentos de transtornos de personalidade. Entretanto poucos estudos avaliam essa modalidade de tratamento para outros tipos de transtorno. Com foco em aspectos intrapsíquicos e interpessoais, Odlaug, Schreiber e Grant (2013) consideram que a PP pode ser útil no tratamento de transtornos do controle do impulso e transtornos relacionados a dependências, especialmente no TJ.

\section{Psicoterapia psicodinâmica}

\section{Contribuições da psicanálise}

A PP se faz presente em diversos programas de tratamento de TJ, e alguns autores teceram considerações acerca dessa patologia já no início do século passado. Em 1914, surgiu a primeira contribuição da psicanálise sobre o jogo patológico, sendo que a primeira psicanálise de um jogador foi retratada em 1920 (Bolen \& Boyd, 1968). Esses autores, em revisão da literatura da época, citam fatores mencionados no início do século XX: prazer erótico associado ao ato de apostar; medo e tensão provocados pelo jogo apontados como de natureza sexual; importância das superstições e dos rituais no pensamento onipotente do jogador e o jogo como defesa contra depressão.

Em Dostoievsky e o parricídio, Freud (1928/2014) tenta explicar a paixão de Dostoievsky pelo jogo. O autor descortina possíveis aspectos psíquicos de Dostoievsky, que padecia de sintomas neuróticos, antes e após o trágico assassinato de seu pai. Há relatos de que, na sua infância, vivenciara ameaça iminente de morte. Freud interpreta esse fato como identificação com um morto ou com alguém que se desejava destruir - no caso, o próprio pai. O ataque histérico seria punição engendrada por esse desejo de destruição. Além disso, o jogo irrompe em sua vida como uma espécie de autoaçoitamento pela culpa, que o levava a dilapidar todo seu patrimônio. Quando o sentimento de culpa ficava satisfeito pelo castigo autoinfligido, a inibição sobre seu trabalho se tornava menos grave e ele se permitia dar alguns passos na estrada do sucesso. Nas linhas finas do texto escrito por Freud, a masturbação é mencionada, as apostas seriam um substituto da masturbação, uma brincadeira irresistível que, após o término do ato, instiga a culpa e a promessa de nunca mais executá-la. Na mesma linha, Fenichel (1981) observa que o jogo patológico teria como etiologia os conflitos relacionados à masturbação, e a excitação que o jogador experimenta no ato de jogar corresponderia à excitação sexual. Ao ganhar o jogo, o jogador experimentaria prazer, ao perder a aposta, castigo pela castração.

Bergler (1957) estudou e tratou extensamente de jogadores pela psicanálise e postulou o paradoxo do desejo inconsciente de perder do jogador, que se manifesta na certeza ilógica de que vai ganhar. Acredita que traços inconscientes de pensamento mágico e onipotentes prevalecem sobre a inteligência. $\mathrm{O}$ jogo reativa sentimentos de megalomania infantis e, ao mesmo tempo, faz reviver sentimentos de rebelião latente contra os pais e representantes da lei. A agressividade inconsciente resulta em culpa e, consequentemente, em necessidade de punição. Onipotência, agressão, culpa e desejo de punição estariam relacionados ao prazer da tensão do jogo.

Rosenthal (1986), por sua vez, compreende o Jogo Patológico distanciando-se do complexo de Édipo e elucidando-o como fenômeno que traz traços narcisistas de personalidade. $\mathrm{O}$ autor aponta mecanismos de defesa egoicos utilizados expressivamente na dinâmica do jogador patológico para lidar com suas angústias, como onipotência e negação. Em 1994, Rugle e Rosenthal apresentaram um modelo de PP para tratar TJ em que, na primeira fase, o objetivo imediato seria a abstinência e sugerem cinco estratégias: romper com o mecanismo de negação, confrontar defesas onipotentes, interromper o ciclo de recuperar o dinheiro perdido em apostas anteriores, identificar razões para o jogo e motivar o paciente a participar ativamente no tratamento.

Haustien e Schurgers (1992) entendem que o jogo patológico é uma tentativa de resolver conflitos intrapsíquicos. O jogo, um objeto inanimado, possibilita o estabelecimento de uma simbiose com claras limitações, uma vez que acaba sempre que a casa de jogo fecha ou que o dinheiro termina. Segundo esses autores, o jogador patológico tem dificuldade em lidar com a separação da mãe na primeira infância, comprometendo assim todo seu desenvolvimento em termos de relação objetal e, consequentemente, a formação de vínculos afetivos.

\section{Contribuições da neurobiologia}

O desenvolvimento de novas tecnologias e o aumento de pesquisas interdisciplinares vêm contribuindo para uma melhor compreensão das patologias, bem como de suas etiologias. Estudos recentes mostram que dependências comportamentais, como o TJ, são semelhantes à dependência de substâncias em muitos aspectos: comorbidade, curso, contribuição genética, neurobiologia, fenomenologia (fissura, intoxicação, abstinência), tolerância e resposta a tratamento (Love, Laier, Brand, Hatch, \& Hajela, 2015). Substrato neurobiológico comum entre TJ e dependência de substâncias vem sendo relatado (Yau \& Potenza, 2015). O processo de tomada de decisão tem papel central no TJ, uma vez que o que caracteriza esse transtorno é o fato de o indivíduo escolher comportamento que provoca sensação de prazer imediato em vez de resistir e optar por recompensa futura. Dificuldade de resistir a impulso associado à recompensa imediata, apesar das consequências negativas, tem sido atribuída à má regulação entre o sistema límbico e córtex pré-frontal (VerdejoGarcía \& Bechara, 2009). A presença de fatores genéticos 
(sistema dopaminérgico e serotonérgico), ambientais (como negligência e/ou abuso físico, sexual, emocional) e estresse contribuiriam para alguns indivíduos serem mais propensos a desenvolver dependências do que outros, uma vez que esses fatores podem promover cicatrizes em áreas pré-frontais e límbicas, podendo inclusive ser transmitidos a gerações futuras (Bock et al., 2014).

\section{Contribuições contemporâneas}

Alvarez-Montjaras, Mayes, Potenza e Rutherford (2018) apresentam um modelo de desenvolvimento de dependências que integra neurobiologia e psicodinâmica pelo viés do apego. Esses autores defendem que dependência pode ser compreendida como um transtorno do desenvolvimento no qual fatores genéticos, epigenéticos e neurobiológicos interagem com experiências adversas de cuidado que ocorrem em fases determinantes do desenvolvimento, aumentando o risco de dependência no futuro. Os autores enfatizam que laços seguros de apego protegem de dependências, promovem desenvolvimento de função executiva e autorregulação. Genes modulam a susceptibilidade à dependência, mas é a interação com o meio ambiente que é determinante.

Essa postura é consonante com diversos teóricos contemporâneos que adotam uma perspectiva biopsicossocial, procurando integrar corpo, cérebro, mente e meio ambiente. A teoria moderna de apego enfatiza o papel central da regulação dos afetos no desenvolvimento e traz contribuições para o tratamento, explicitando a relevância da PP. Shore (2012) formulou a Teoria de Regulação dos Afetos a partir de pesquisas interdisciplinares que sugerem que a organização do cérebro em desenvolvimento acontece na relação com outro cérebro. $\mathrm{O}$ desenvolvimento do hemisfério direito e sistema límbico, regiões associadas à comunicação não verbal e memória implícita se desenvolvem antes do córtex pré-frontal. A intersubjetividade se desenvolve desde muito cedo, havendo comunicação não verbal entre hemisfério direito da mãe e da criança, que registra as experiências vividas formando a memória implícita. Se tudo ocorrer de forma satisfatória, conforme a criança vai crescendo, ela desenvolve a teoria da mente, capacidade reflexiva e simbólica, e aprende a se autorregular. Padrão de apego seguro proporciona melhores condições para desenvolvimento normal, competência emocional e base para aprendizagem. Relações de apego traumáticas podem prejudicar a capacidade de lidar com agentes estressores durante a vida.

Apesar de as experiências precoces serem determinantes tanto no desenvolvimento neurobiológico quanto psicológico, novos conhecimentos sobre processamento de informações e plasticidade cerebral indicam ser cada vez mais clara a possibilidade de reparação de danos e criação de novas estruturas para lidar melhor com as demandas da vida, por meio de relações empáticas e significativas (Cozolino, 2016;
Gerhardt, 2015; Knox, 2011; Shore, 2012; Wilkinson, 2010). Shore (2012) afirma que a teoria moderna de apego enfatiza o papel central da regulação dos afetos no desenvolvimento e no tratamento, destacando a importância da intersubjetividade na relação terapêutica. O conhecimento do papel do hemisfério direito subjacente à comunicação não verbal é essencial. O processo analítico promove integração e o resgate de memórias somáticas e emocionais relacionadas ao hemisfério direito e memórias consciente relacionadas ao esquerdo, favorecendo a autorregulação. $\mathrm{O}$ estabelecimento de um vínculo seguro possibilita que a interpretação, que converte emoções em palavras, favoreça a conectividade e o funcionamento integrado dos dois hemisférios (Wilkinson, 2010). O terapeuta propicia um olhar de fora, facilitando a possibilidade de ressignificar vivências e coconstruir narrativas (Cozolino, 2016). Atitude empática do terapeuta ajuda a regulação do afeto, uma vez que se torna possível interpretar o mundo interno do paciente e ajudá-lo a aprimorar a função reflexiva, aumentando sua capacidade de simbolizar (Knox, 2011). Esse tipo de intervenção amplia a consciência favorecendo a possibilidade de criar tempo para pensar entre impulso e ação, aspecto importante quando se trata de jogadores, muitas vezes bastante impulsivos.

\section{A experiência da Psicoterapia Psicodinâmica no PRO-Amjo}

Os jogadores que procuram o PRO-Amjo passam por uma triagem para confirmação diagnóstica e investigação de comorbidades, sendo posteriormente encaminhados para acompanhamento clínico e psicológico. A psicoterapia psicodinâmica individual é composta por 40 sessões de 50 minutos. Se o paciente faltar três vezes sem justificativa, é desligado da psicoterapia, mas permanece vinculado ao serviço. $\mathrm{O}$ atendimento é realizado por psicólogos voluntários do PRO-Amjo, que passaram por uma formação em transtornos do controle do impulso oferecida pelo próprio programa. A orientação psicodinâmica dos psicólogos que compõe a equipe é variada, havendo profissionais que estudam diferentes vertentes da psicanálise e psicologia analítica. A supervisão é semanal, conduzida por um profissional com experiência na área. Na supervisão, procura-se uma visão psicodinâmica abrangente, integrando conceitos de psicanálise, psicologia analítica e teoria de regulação emocional, na condução do processo psicoterápico.

Até o momento ainda não há estudo sobre eficácia de PP para jogadores no PRO-Amjo. No entanto pesquisa conduzida por Magalhães (2011) sobre análise de discurso de pacientes e terapeutas envolvidos em psicoterapia de orientação psicodinâmica identificou alguns elementos relevantes para essa abordagem com jogadores. Terapeutas foram unânimes em atribuir papel central à transferência no tratamento, havendo diferença entre eles no manejo. Foram relatadas defesas 
narcísicas e onipotentes, como fantasias de grandes vitórias, querer ser exceção, ser poderoso e estar no controle. Na fase inicial da PP, observou-se que os pacientes costumam negar o problema, não mostrando interesse pelo tratamento e apresentando dificuldade em se responsabilizar pelos seus atos. Na fase intermediária, houve maior aproximação entre os discursos de terapeutas e pacientes e na final, observou-se no discurso dos terapeutas considerável idealização do término do processo. O estudo ressalta a importância de preparar terapeutas para lidar com defesas, conflitos, resistências típicas de jogadores e trabalhar sentimentos de abandono e luto que habitualmente emergem ao fim da terapia.

Rosenthal (2008), em artigo sobre PP e tratamento para TJ, enfatiza que a PP foca nos afetos e na expressão das emoções do paciente, na identificação dos padrões de ações, pensamentos e sentimentos. As experiências e relações do paciente são exploradas no tratamento, assim como os desejos, os sonhos e as fantasias, incluindo tentativas do paciente de evitar tópicos ou engajar-se em atividades que prejudiquem o progresso da terapia (evitação, resistência). Nessa abordagem, enfatizam-se experiências passadas, relacionamentos interpessoais, desejos e conflitos inconscientes. Utilizando-se como modelo o relacionamento pacienteterapeuta, busca-se auxiliar o paciente a compreender e cessar comportamentos autodestrutivos. Aspectos como empatia, atenção flutuante e autorreflexão são fundamentais durante todo o atendimento. Transferência e contratransferência são levadas em consideração, sendo fonte de informação do andamento do processo. A experiência vivida na relação analítica é mais importante do que as interpretações. Leva-se em conta a comunicação não verbal.

Levando em consideração os aspectos mencionados, nos atendimentos de PP do PROAmjo, parte-se da importância da relação terapêutica. A intersubjetividade tem papel fundamental, uma vez que propicia a cocriação de narrativas e de histórias coerentes que podem promover interação neural e psíquica. Todo o trabalho é, portanto, baseado no vínculo e em uma escuta analítica qualificada. Algumas perguntas básicas norteiam o processo psicoterapêutico, como: quem é essa pessoa? Por que procura o serviço nesse momento? O que está acontecendo na sua vida? Veio espontaneamente, por pressão familiar ou outro motivo? O que e como joga? Com que frequência? Qual a história do jogo na vida dessa pessoa? Nas sessões, o terapeuta procura ajudar o jogador a identificar o que sente, nomear e compreender como se relaciona com isso. Auxilia-o a olhar as consequências negativas e os ganhos secundários inconscientes do seu comportamento. A grande pergunta a ser elucidada ao longo do processo psicoterapêutico é: qual função o jogo ocupa na vida dessa pessoa? Como ajudá-la a criar consciência dessa dinâmica e mudar seu padrão de funcionamento?
O indivíduo é convidado a rever sua história, procurando ressignificar vivências, elaborar perdas, resgatar recursos internos e abrir espaço para sua singularidade. O terapeuta ajuda o jogador a sustentar a possibilidade de deparar com suas verdadeiras questões e resgatar seu processo de individuação (Oliveira, 2005). Durante as sessões, há a possibilidade de reconstruir narrativas e assim favorecer a mudança de comportamento. Procura-se promover um diálogo interno, em que o paciente aprende a dar nome a estados internos e interagir com eles, saindo do padrão automático, diferenciando impulso da ação, conforme defende Siegel (2007). O terapeuta vai reforçando qualidades e habilidades do jogador para ajudá-lo a enfrentar dificuldades, suportar frustração, aguentar tensão, para transcender e chegar a um novo padrão de relacionamento consigo mesmo e com o mundo. A comunicação não verbal tem papel relevante, sendo trabalhada na transferência e na contratransferência.

\section{Alguns perfis característicos de jogadores}

Ao longo das sessões, muitos jogadores relatam história prévia de vínculos frágeis e situações de sofrimento intenso na infância, como abuso parental, pais agressivos, alcoolistas ou dependentes de outras drogas. Observam-se comportamentos típicos ou padrões comuns a portadores de TJ, como sentimento de culpa, ansiedade, solidão e desamparo, além de impulsividade e dificuldade de lidar com frustração. Há casos em que prepondera um pensamento mágico. São indivíduos que se iludem, mentem a si mesmos e aos outros, tendo dificuldade em lidar com os desafios de crescer, se diferenciar, sair do lugar de dependente e assumir as consequências de seus atos. Alguns ficam presos no lugar de filho eterno, não acessam seus aspectos infantis inconscientes e projetam na família e no ganho financeiro a resolução de seus problemas. Algumas frases exemplificam esses casos, tais como "fiz arte, joguei de novo" ou "vou dar outro trabalho para minha mãe. Não paguei o aluguel, usei o dinheiro para jogar e, agora, ela vai ter que pagar novamente o meu aluguel".

Um perfil que aparece com frequência entre os jogadores que procuram tratamento é aquele em que o sujeito acreditava que tudo ia bem na sua vida, até que um evento que lhe parece repentino, como uma separação, demissão, aposentadoria, o desestrutura. Nesses casos, fica evidente a dificuldade em lidar com angústia e frustração, e o jogo aparece como refúgio. Nos atendimentos, surgem conteúdos dissociados, evidenciando que o indivíduo não percebia o que se passava consigo e à sua volta. Frequentemente, esses pacientes não conseguem identificar o que sentem, do que realmente necessitam, nem encontrar maneiras de suprir essa falta de forma apropriada. Muitos relatam situações de negligência ou de abuso na infância que 
não foram elaboradas. Precisam aprender a reconhecer suas reais necessidades e pedir ajuda para não mais agir impulsivamente, tentando se livrar de um mal-estar difuso. No processo psicoterápico, é comum demonstrarem raiva e culpa pelo dinheiro que perderam, pela mudança no padrão de vida, pela falta de autonomia e, além disso, pela impotência que sentem ao terem que pedir dinheiro para os outros. O contato com o que sentem mostra-se muito superficial, sendo difícil irem além do "estou triste" ou "fiquei feliz". Na medida em que o trabalho psicoterápico progride, passam a entrar em contato com sentimentos de maneira mais profunda e lidar com eles de forma mais adequada.

É comum surgirem nas sessões relatos de sensação de tédio e monotonia, como se nada - trabalho, relação amorosa e lazer - fosse tão prazeroso como jogar, assim como queixas de que as pessoas não compreendem sua relação com o jogo. Nos atendimentos, frequentemente evidencia-se uma ausência de consciência no jogador acerca do impacto de seu comportamento na vida de pessoas próximas, como cônjuges e filhos. A dissociação é um mecanimo de defesa muito frequente. Como não toleram angústia, dissociam, minimizam ou projetam em fatores externos.

Outra faceta comum é a do jogo como forma inconsciente de solicitar auxílio e cuidado. São pessoas que passaram a vida inteira cuidando dos outros e não aprenderam a cuidar de si mesmas, a reconhecer suas carências e a pedir ajuda. Inteligentes, generosos e bem-sucedidos, tornaram-se independentes cedo e apostaram cada vez mais alto para se manter nesse padrão. Nesses casos, observa-se muita dificuldade em sair da postura onipotente, assumir vulnerabilidades e pedir auxílio. Apresenta-se, a seguir, um exemplo desse tipo de jogador.

Uma empresária de 60 anos, divorciada, relata ter sido sempre muito rígida e determinada, uma verdadeira workaholic. De funcionária passou a dona do negócio, ganhou muito dinheiro e fez fortuna. Educou os filhos em colégios caros, comprou casa, carro, casa na praia etc. Contudo, quando os filhos cresceram, passou a se sentir muito sozinha. Aos finais de semana, levava-os para a "balada" e, depois, se ausentava do mundo dentro das casas de jogo. Suas apostas eram altas. Chegava a ficar oito horas apertando botão acreditando que era capaz de desenvolver uma lógica para ganhar da maquininha, uma fantasia comum a jogadores. Mesmo ganhando quantias elevadas algumas vezes, perdeu tudo que possuía e endividou-se. Durante o processo psicoterápico, evidenciou-se a dinâmica "do tudo ou nada", não tolerando erros explicitando sua dificuldade em se perdoar e aceitar limites.

Entre idosos, é possível identificar outra faceta da atividade de jogar. $\mathrm{O}$ jogo aparece como inserção social e ocupação em uma fase de vida empobrecida, marcada pela aposentadoria e limitações. Neste caso, também se observa a crença em soluções mágicas e onipotentes. Sentindo falta dos benéficos que o trabalho proporcionava, como renda, ocupação e vida social, passam a frequentar casas de jogo buscando esses benefícios, mas alguns acabam entrando em um ciclo vicioso do TJ.

\section{Considerações finais}

Jogos de azar entraram na vida de portadores de TJ primordialmente como distração, algumas vezes como tentativa de apaziguar um humor disfórico ou forma de ganhar dinheiro, mas acabaram provocando o contrário. Apesar dos importantes prejuízos provocados pelo excesso de apostas nos diferentes jogos de azar, são raros os serviços que atendem TJ no Brasil. Existem diferentes abordagens psicoterápicas para tratar esse transtorno, sendo a psicoterapia de abordagem psicodinâmica um recurso importante a ser utilizado, uma vez que propicia a autorregulação dos afetos. A partir da relação terapêutica empática, é possível trazer elementos inconscientes que estão subjacentes ao padrão comportamental autodestrutivo para a consciência, favorecendo a instalação e manutenção de comportamentos mais benéficos e construtivos na vida dos pacientes.

Muitos jogadores relatam histórias prévias de abuso ou negligência. Parece que conseguiram fugir da situação adversa, se armando para vencer os mais diversos desafios, mas uma ferida ficou na base. Como no mito de Ícaro, na fuga, se excedem. A autorregulação falha e, em determinado momento, inflam, voam alto demais e põem tudo a perder. De provedores, passam a ter que receber cuidados e a aprender a viver entre a onipotência e a impotência. Outros jogadores ficam presos no polo oposto, tendo dificuldade em crescer, se diferenciar e assumir responsabilidades, ficando acomodados no papel de filho. Sacrificar, aceitar as perdas, perdoar-se e conviver com as possibilidades existentes é o grande desafio de todos.

Nos atendimentos, busca-se trazer à luz os recursos internos de cada um para que, em momentos difíceis, seja possível acessar outras alternativas que não o jogo. Procura-se acessar conteúdos inconscientes e integrá-los, elaborando vivências precoces para saírem da estagnação em que se encontram, se perdoarem e romperem com o ciclo culpa/castigo que os aprisionam. Essa construção de uma vida possível, entre "tudo e nada", é desenvolvida durante as sessões. A construção de uma relação genuína com o terapeuta a partir de um vínculo seguro possibilita o início de uma nova maneira, desta vez mais saudável, de se relacionar consigo e com o mundo. 


\section{Gambling Disorder: contributions of the psychodynamic approach to treatment}

Abstract: Gambling may be a leisure activity, but overdoing it can lead to adverse consequences such as Gambling Disorder. Despite the serious damage caused by the disorder, both Gambling Disorder and its treatment strategies are little known in Brazil. This study investigates Gambling Disorder and its treatment, emphasizing the contributions of the psychodynamic approach. The paper presents the main psychodynamic hypotheses in the literature and comments on the psychodynamic psychotherapy carried out in facilities treating pathological gamblers in São Paulo, such as the Pathological Gambling Outpatient Program (PROAMJO) of the Psychiatric Institute of Hospital das Clínicas (IPq HC-FMUSP). Finally, some examples of pathological gambler profiles are discussed.

Keywords: Gambling Disorder, pathological gambling, treatment, psychodynamic, psychotherapy.

\section{Jeu Pathologique : contributions de l'approche psychodynamique au traitement}

Résumé : Le jeu de hasard peut être un loisir, mais l'excès peut avoir des conséquences néfastes, comme le Jeu Pathologique. Malgré les graves consequences causés par ce trouble, le Jeu Pathologique et ses stratégies de traitement sont peu connus au Brésil. Cettte étude porte sur la Dépendence au jeu et son traitement, en mettant l'accent sur les contributions de l'approche psychodynamique. L'article présente les principales hypothèses psychodynamiques dans la littérature et reflète sur la psychothérapie psychodynamique réalisée dans les services qui s'occupent de joueurs à São Paulo, telles que le Programma ambulatoire sur la dépendance au jeu (PRO-AMJO) del'Institut de psychiatrie de l'Hospital das clínicas (IPq HC-FMUSP). Enfin, quelques exemples de profils de joueurs pathologiques sont discutés.

Mots-clés : Jeu pathologique, traitament, psycodynamique, psicotherapie.

\section{Trastorno de Juego: contribución del enfoque psicodinámico al tratamiento}

Resumen: Los juegos de azar pueden ser una actividad de diversión, pero su práctica excesiva puede traer consecuencias adversas como el Trastorno de Juego. A pesar de los graves daños causados por este comportamiento, tanto el Trastorno de Juego en sí como las estrategias de tratamiento son poco conocidos en Brasil. Este trabajo aborda el Trastorno de Juego y su tratamiento, con el objetivo de hacer explícito la contribución del enfoque psicodinámico. Se presentan las principales hipótesis psicodinámicas en la literatura y se hacen consideraciones sobre la psicoterapia psicodinámica realizada en un servicio que atiende a jugadores en São Paulo, como el Programa del Hospital das Clínicas de la Facultad de Medicina de la Universidad de São Paulo (IPq HC-FMUSP). Finalmente, se presentan algunos ejemplos de perfiles de jugadores patológicos.

Palabras clave: Trastorno de Juego, juego patológico, tratamiento, psicodinámica, psicoterapia.

\section{Referências}

Alvarez-Montjaras, M., Mayes, L. C., Potenza, M. N., \& Rutherford, H. J. V. (2018). A developmental model of addiction: integrating neurobiological and psychodynamic theories though the lens of attachment. Attachment and Human Development, 21(6), 616-637. doi: 10. 1080/14616734.2018.1498113

American Psychiatric Association. (1980). Diagnostic and statistical manual of mental disorders III (4th ed.). Washington, DC: American Psychiatric Association.

American Psychiatric Association. (2013). Diagnostic and statistical manual of mental disorders $V$ (4th ed.). Washington, DC: American Psychiatric Association.

Bergler, E. (1957). The Psychology of Gambling. New York: Hill \& Wang.
Bock, J., Rether, K., Groger, N., Xie, L., \& Braun, K. (2014). Perinatal programming of emotional brain circuits: an integrative view from systems to molecules. Frontiers in Neuroscience, 8, 1-11. doi: 10.3389/ fnins.2014.00011

Bolen, D. W., \& Boyd, W. H. (1968). Gambling and the gambler: a review and preliminary findings. Arch Gen Psychiatry, 18(5), 617-630. doi: 10.1001/ archpsyc.1968.01740050105018

Cozolino, L. (2016). Why therapy works: using our mind to change our brains. New York: W. W. Norton \& Company.

Custer, R. L. (1984). Profile of the pathological gambler. The Journal of Clinical Psychiatry, 45(12), 35-38. 
Desai, R. A., \& Potenza, M. N. (2008). Gender differences in the associations between past-year gambling problems and psychiatric disorders. Social Psychiatry and Psychiatric Epidemiology, 43(3), 173-183. doi: 10.1007/ s00127-007-0283-z

Dostoievsky, F. (1987). O jogador. Rio de Janeiro, RJ: Bertrand Brasil. (Trabalho original publicado em 1866)

Fenichel, O. (1981). Teoria psicanalitica das neuroses. Rio de Janeiro, RJ: Atheneu.

Fong, T. W. (2005). Types of psychotherapy for pathological gamblers. Psychiatry, 2(5), 32-39.

Freud, S. (2014). Dostoievsky e parricídio. In Obras completas: Inibição, sintoma e angústia, o futuro de uma ilusão e outros textos (Paulo César de Souza, Trad., Vol. 17 pp. 337-364). São Paulo, SP: Companhia das Letras. (Trabalho original publicado em 1928)

Gerhardt, S. (2015). Por que o amor é importante: como o afeto molda o cérebro do bebê. Porto Alegre, RS: Artmed.

Håkansson, A., \& Ford. M. (2019). The General population's view on where to seek treatment for gambling disorder: a general population survey. Psychology Research and Behavior Management, 19(12), 1137-1146. doi: 10.2147/PRBM.S226982

Haustien, J., \& Schurgers, G. (1992). Therapy with male pathological gamblers: between self- help groups and group therapy - report of a developmental process. Journal of Gambling Studies, 8(2), 131-142. doi: 10.1007/BF01014631.

Huizinga, J. (1999). Homo Ludens (4a ed.). São Paulo, SP: Perspectiva. (Trabalho original publicado em 1938)

Tang, K. T. Y., Kim H. S., Hodgins D. C., McGrath, D. S., \& Tavares, H. (2020). Gambling disorder and comorbid behavioral addictions: Demographic, clinical, and personality correlates. Psychiatry Research, 284, 112763. doi: 10.1016/j.psychres.2020.112763

Knox, J. (2011). Self-Agency in psychotherapy. New York: W. W. Norton \& Company.

Kraus S. W, Etuk R, Potenza M. N. (2020). Current pharmacotherapy for gambling disorder: a systematic review. Expert Opin Pharmacother, 21(3), 287-296. doi: 10.1080/14656566.2019.1702969

Love T., Laier C., Brand M., Hatch L, \& Hajela, R. (2015). Neuroscience of internet pornography addiction: A review and update. Behavioral Sciences, 5(3), 388433. doi: 10.3390/bs5030388

Magalhães, A. C. N. (2011). Tratamento de jogadores patológicos com o uso de técnica psicodinâmica: análise qualitativa do discurso de terapeutas $e$ pacientes (Dissertação de Mestrado). Universidade de São Paulo, São Paulo, SP. doi: 10.11606/D.5.2011.tde09112011-163600

Mladenoviü, I., Lažetiü, G., Lepiü-Toševski, D., \& Dimitrijeviü, I. (2015). Treatment of pathological gambling: integrative systemic model. Psychiatria Danubina, 27(1), 107-111.

Odlaug, B. L., Schreiber, L. R., \& Grant, J. E. (2013). Personality dimensions and disorders in pathological gambling. Current Opinion in Psychiatry, 26(1), 107112. doi: 10.1097/YCO.0b013e32835997df

Oliveira, M. P. M. T. (2005). Dependências: O homem à procura de si mesmo. São Paulo, SP: Ícone.

Oliveira, M. P. M. T. (2009). Trastorno de Juego patológico. In M. Saiz (Org.), Psicopatologia Psicodinamica Simbólica-arquetípica (Vol. 2, pp. 63-80). Montevidéu: Prensa Medica Latinoamericana Helber Saldivia.

Oliveira, M. P. M. T., \& Silva, M. T. A. (1998). Jogo patológico: uma revisão da literatura. Revista $A B P$ APAL, 20(4), 179-187.

Petry, N. M., Ginley, M. K., \& Rash, J. C. (2017). A systematic review of treatments for problem gambling. Psychology of Addictive Behaviors, 31(8), 951-961. doi: 10.1037/ adb0000290

Petry, N. M., Stinson, F. S., \& Grant, B. F. (2005). Comorbidity of DSM-IV pathological gambling and other psychiatric disorders: results from the National Epidemiologic Survey on Alcohol and Related Conditions. The Journal of Clinical Psychiatry, 66, 564-574. doi: 10.4088/jcp.v66n0504

Rosenthal, R. J. (1986). The pathological gambler's system for self-deception. Journal of Gambling Behavior, 2, 108-120. doi: 10.1007/BF01019629

Rosenthal, R. J. (2008). Psychodynamic psychotherapy and the treatment of pathological gambling. Brazilian Journal of Psychiatry, 30(1), S41-50. doi: 10.1590/ s1516-44462008005000004

Rugle, L. J., \& Rosenthal, R. J. (1994). Transference and countertransference reactions in the psychotherapy of pathological gamblers. Journal of Gambling Studies, 10(1), 43-65. doi: 10.1007/BF02109778

Shedler, J. (2010). The efficacy of psychodynamic psychotherapy. American Psychological Association, 65(2), 98-109. doi: $10.1037 / \mathrm{a} 0018378$

Shore, A, N. (2012). The science of the art of psychotherapy. New York: W. W. Norton \& Company.

Siegel, D. J. (2007). The mindful brain: reflection and attunement in the cultivation of well-being. New York: W. W. Norton \& Company.

Stea, J. N., \& Hodgins, D. C. (2011). A critical review of treatment approaches for gambling disorders. Current Drug Abuse Reviews, 4(2), 67-80. doi: 10.2174/1874473711104020067

Tavares, H. (2014). Gambling in Brazil: a call for an open debate. Addiction, 109(12), 1972-1976. doi: 10.1111/ add. 12560

Tavares, H., Carneiro, E., Sanches, M., Pinsky, I., Caetano, R., ...Laranjeira, R. (2010). Gambling in Brazil: lifetime prevalences and socio-demografic correlates. Psychiatry Research, 180(1), 35-41. doi: 10.1016/j. psychres.2010.04.014

Verdejo-García, A., \& Bechara, A. (2009). A somatic marker theory of addiction. Neuropharmacology, 56(Suppl 1), 48-62. doi: 10.1016/j.neuropharm.2008.07.035

Walker, M., Toneatto, T., Potenza, M. N., Petry, N, Ladouceur, R., Hodgins, D. C., ...Blaszczynski A. 
(2006). A framework for reporting outcomes in problem gambling treatment research: The Banff, Alberta, Consensus. Addiction, 101(4), 504-511. doi: 10.1111/j.1360-0443.2005.01341.x

Wilkinson, M. (2010). Changing minds in therapy: emotion, attachment, trauma and neurobiology. New York: W. W. Norton \& Company.
Yau, Y. H., \& Potenza, M. N. (2015). Gambling disorder and other behavioral addictions: recognition and treatment. Harvard Review of Psychiatry, 23(2), 134-146. doi: 10.1097/HRP.0000000000000051

Recebido: $21 / 01 / 2021$

Aprovado: 04/08/2021 


\section{Agradecimentos}

Ao prof. dr. Hermano Tavares e equipe do PRO-Amjo, pelo incentivo e apoio sem os quais este trabalho não seria possível. 